\title{
Dynamic Behavior of Solder Filling during Ultrasonic Soldering
}

\author{
What's claimed to be the first in-situ observations of capillary filling and \\ acoustic cavitation during ultrasonic soldering were illustrated
}

BY Z. XU, Z. LI, L. MA, Z. CAO, J. YANG, AND J. YAN

\begin{abstract}
In this work, the dynamic behavior of solder filling in a nonwetting joint capillary under ultrasonic agitation was visually observed by using a high-speed camera. The filling process, sputtering of solder, and cavitation phenomena were recorded and discussed. Filling variation was correlated with ultrasonic power, base material type, and clearance width. Notably, the filling rate of liquid metal varied along the joint clearance and was dependent on the surface vibration strength of the substrate. The sputtering and cavitation of liquid metal became pronounced when the surface vibration of the base material exceeded a critical value. High ultrasonic power, high base material stiffness, and narrow clearance increased filling rate. The evidence in this research showed cavitation is not necessary for initiation of the ultrasonic capillary effect.
\end{abstract}

\section{KEYWORDS}

- Ultrasonic Soldering • Capillary • Cavitation

- Ultrasonic Power • Clearance Width

\section{Introduction}

Ultrasonic soldering involves the induction of highfrequency mechanical vibrations into molten solder and the induction of cavitation (Ref. 1). Cavitation stresses disrupt and disperse oxide layers and other contaminants on the surfaces of the components covered by the molten solder. These phenomena enable the molten solder to wet the clean surfaces of the base material surfaces (Refs. 2, 3). In contrast to conventional soldering, ultrasonic soldering can do the following: 1) solder materials containing resistant surface oxides, such as $\mathrm{Al}, \mathrm{Mg}, \mathrm{Ti}$, and their alloys (Refs. 4, 5); 2) prevent exposure to potentially hazardous materials and postcleaning operations by eliminating flux; and 3) improve joint corrosion resistance by preventing flux entrapment (Refs. 6-8).

The production of high-quality joints through ultrasonic soldering is based on the effective agitation of the molten sol- der and the generation of sufficient cavitation intensity. In the earliest ultrasonic-soldering processes, the solder is directly agitated by an ultrasonic generator (Refs. 9-12). Ultrasonic energy is applied directly to the molten solder either with a soldering iron or solder pot, which is also referred to as a solder bath or solder tank, to promote substrate wetting. Soldering iron is operated at ultrasonic frequencies and internally heated to provide heat and vibration to the solder (Ref. 10). Vibration and cavitation in the molten solder then permit the solder to wet and adhere to the base material surfaces. This process shows high efficiency in applications involving small joint areas but requires the predeposition of the solder on the surfaces of large joint areas, which results in productivity loss. Similar to that of ultrasonic cleaners, the operation of the solder pot involves attaching acoustic transducers directly to the bottom of the pot and inducing cavitation in the volume of the molten solder (Ref. 9). The substrates must be immersed in the solder pool to produce a joint (Ref. 11). The use of the solder pool enables handling of soldering joint batches and drastically increases production. The liquid solder attenuates intensely and rapidly because of its high acoustic impedance as ultrasonic energy is transmitted from the bottom of the solder bath and dispersed within the entire solder. Thus, the intensity and distribution of the cavitation field within the solder pool become complex, and the quality of the soldered joints is highly sensitive to the immersion depth (Ref. 12).

Recently, ultrasonic energy has been coupled with clamping fixtures or base materials to agitate molten solder given the high flexibility and efficient acoustic energy utilization of this approach (Ref. 13). Faridi (Ref. 14) demonstrated the feasibility of the flux-free ultrasonic soldering of $\mathrm{Al}$ and stainless steel lap joints via transmitting the ultrasonic energy through a solid aluminum fixture and base material sheets. Weis et. al. (Ref. 15), Nagaoka et. al. (Refs. 16, 17), Tillmann et. al. (Ref. 18), and Elrefaey et. al.(Ref. 19) coupled a sonotrode directly to the base materials, to transmit ultrasonic energy, that was transmitted to the molten solder. In these studies, solders were preloaded between faying faces without exception. Most researchers likely believed that spontaneous capillary action cannot occur because, in contrast to flux, ultrasound cannot function as a wetting agent to remove the surface oxides of the substrates ahead of the molten solder and to reduce the sur- 


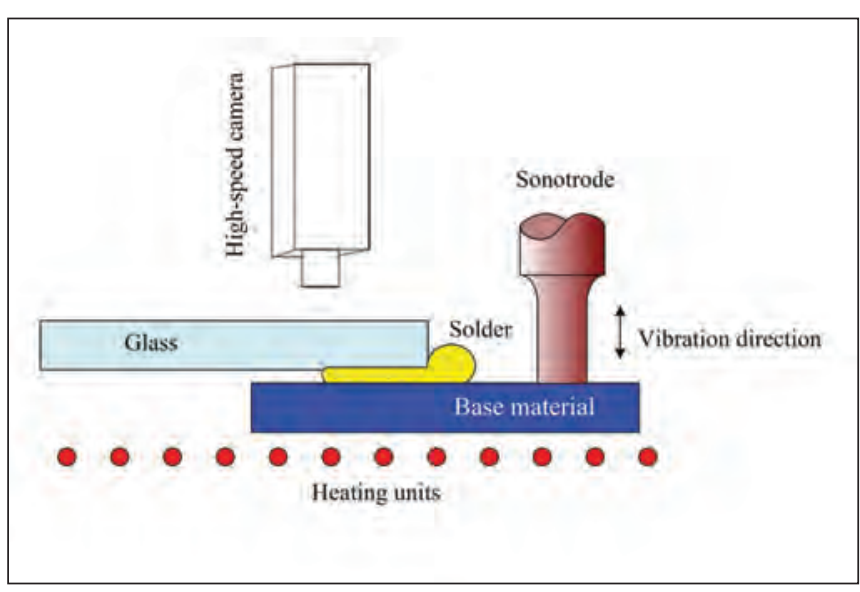

Fig. 1-Schematic of ultrasonic-assisted solder filling.

face tension of the liquid solder. We previously found that even if the liquid solder did not wet the substrate, the solder droplet located at the entrance of the overlap joint readily filled the clearance at an incredibly high rate when ultrasonic waves were imposed on the substrates in air (Refs. 20,21). This phenomenon differed from that observed in flux-assisted or vacuum soldering, wherein capillary filling is entirely dependent on the wetting of the substrates by the liquid solder.

The abnormally rapid ascent/filling of a liquid inside capillaries, canals, pores, and voids when the liquid volume is subjected to a high-intensity ultrasonic field has also been observed in various important technological and chemical processes related to microfluidic systems (Refs. 22,23 ), bio-sludge and biomass processing (Ref. 24), membrane filtration (Ref. 25), ceramic filtration (Ref. 26), microbiology (Ref. 27), and high-quality metal casting (Refs. $28,29)$. This phenomenon is known as the sono-capillary or ultrasonic capillary effect (UCE) and has attracted considerable attention from researchers in the aforementioned fields. Researchers have developed several hypotheses regarding the mechanism underlying the UCE (Refs. 30-36). For example, Malykh et al. (Ref. 32) and Dezhkunov et al. (Ref. 30) correlated cavitation status at entrances of capillary tubes with water capillary rise and suggested that cavitation generation is required for the $\mathrm{UCE}$, given that drastic capillary ascent occurred when a capillary was placed in a developed cavitation area and liquid did not ascend in capillaries in the absence of cavitation. Similarly, Sankin and Malykh (Ref. 33), as well as Tamura and Hatakeyama (Ref. 34), believed the counterpressure arising from the interactions between capillaries and cavitation bubbles that formed at the open ends of the capillaries increased liquid height. In line with these re- search findings was the recent work of Tzanakis et al. (Ref. 37), who observed the UCE in molten $\mathrm{Al}$ in situ by using synchrotron $\mathrm{x}$-ray radiography and hypothesized that the collapse of cavitation bubbles in the vicinity of microcapillary inlets is the possible mechanism responsible for the UCE.

By contrast, Hu et al. (Ref. 38) claimed that the acoustic cavitation is not a necessary condition of UCE, as it may occur in the ultrasonic capillary action. They investigated an ultrasonic actuator that applied ultrasound-induced capillary action to transport miniscule quantities of liquid in a twisted bundle of metal wires, and they proposed that ultrasound energy might weaken cohesive forces among liquid molecules. They also proposed that liquid capillary flow occurs when the adsorption force between the capillary tube and liquid exceeds the cohesive force. Rozina et al. (Ref. 22) also reported that the filling of dead-end capillaries with a liquid in an ultrasonic field was mainly affected by gas dissolution inside the capillary rather than cavitation. Additionally, Cecchini et al. (Ref. 39) demonstrated surface-acousticwave-driven microfluidics in polydimethilsiloxane- $\mathrm{LiNbO}_{3}$ microchannels and showed that the evolution of the atomizing droplets within fluidic channels and their interaction with the liquid meniscus determined rapid fluid movement.

The mechanism governing the UCE remains a point of debate, and the role of cavitation in this phenomenon remains an open subject for further investigation. Therefore, in this research a high-speed camera was used to record the ultrasonically induced filling of liquid solder in a joint clearance. High-speed photography has a faster acquisition rate than synchrotron $\mathrm{x}$-ray imaging technology. Solder filling under ultrasonic exposure and its influential factors were analyzed through high-speed photography combined with finite-element calculation. To the best of our knowledge, this work is the first to observe the dynamics of capillary filling and cavitation in ultrasonic soldering directly. This novel research is a small step toward understanding the nature of ultrasonic soldering.

\section{Experimental Procedures}

\section{Base Materials and Solders}

Pure Al, $5056 \mathrm{Al}$ alloy, and Fe36Ni provided by Northeast Light Alloy Co. Ltd. were used as base materials in this study. The physical and mechanical properties of the base materials are given in Table 1 . The dimensions of the base materials were $50 \times 10 \times 3 \mathrm{~mm}$. The solders used in this work were $\mathrm{Sn}-9 \mathrm{Zn}, \mathrm{Sn}-4 \mathrm{Cu}$, and $\mathrm{Zn}-5 \mathrm{Al}$, which have melting points of $191^{\circ}, 271^{\circ}$, and $380^{\circ} \mathrm{C}$, respectively.

Table 1-Physical and Mechanical Properties of the Base Materials

Material

Modulus of Elasticity (GPa)

Density $\left(\mathrm{kg} / \mathrm{cm}^{3}\right)$

Poisson's Ratio

Pure Al

$5056 \mathrm{Al}$

$\mathrm{Fe} 36 \mathrm{Ni}$
68.9

71.7

142
2.7

2.64

8.1
0.31

0.31

0.31 

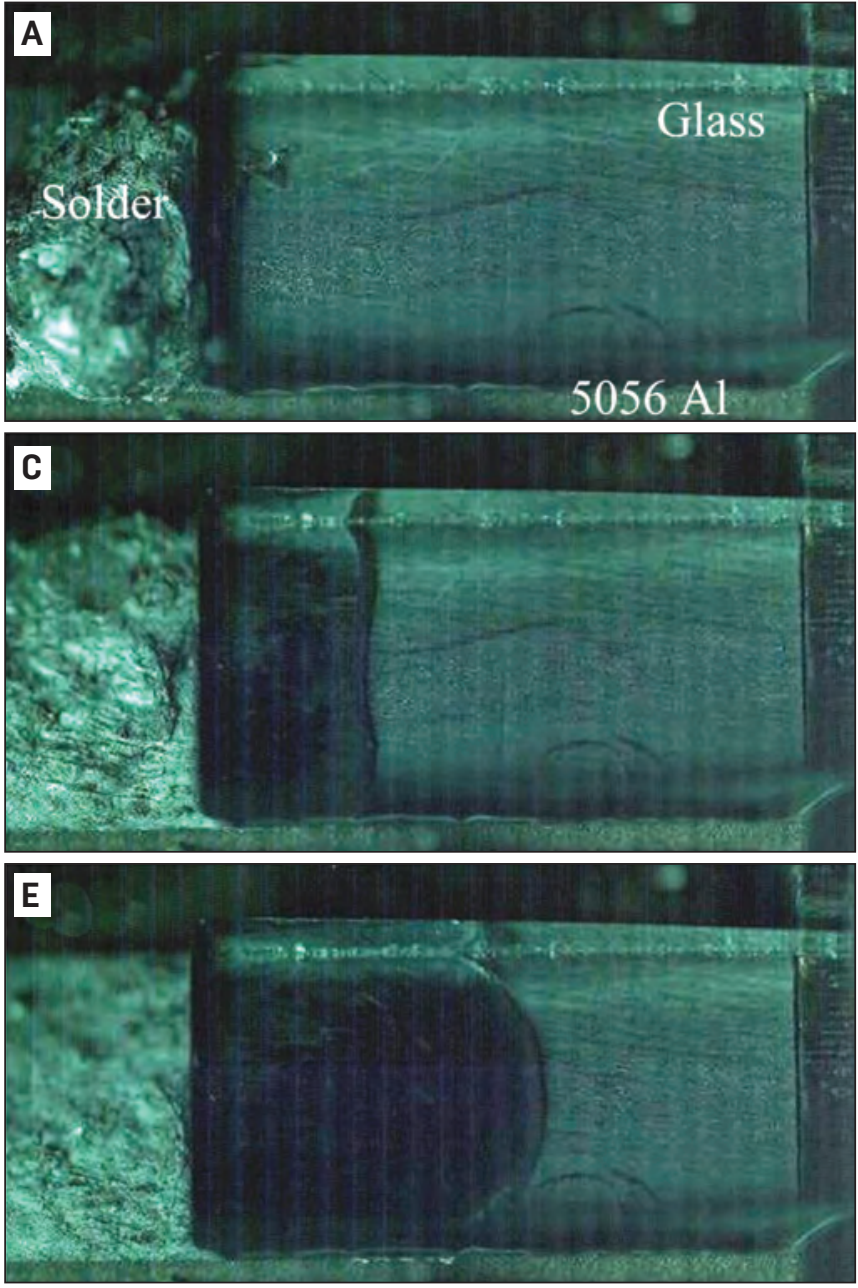
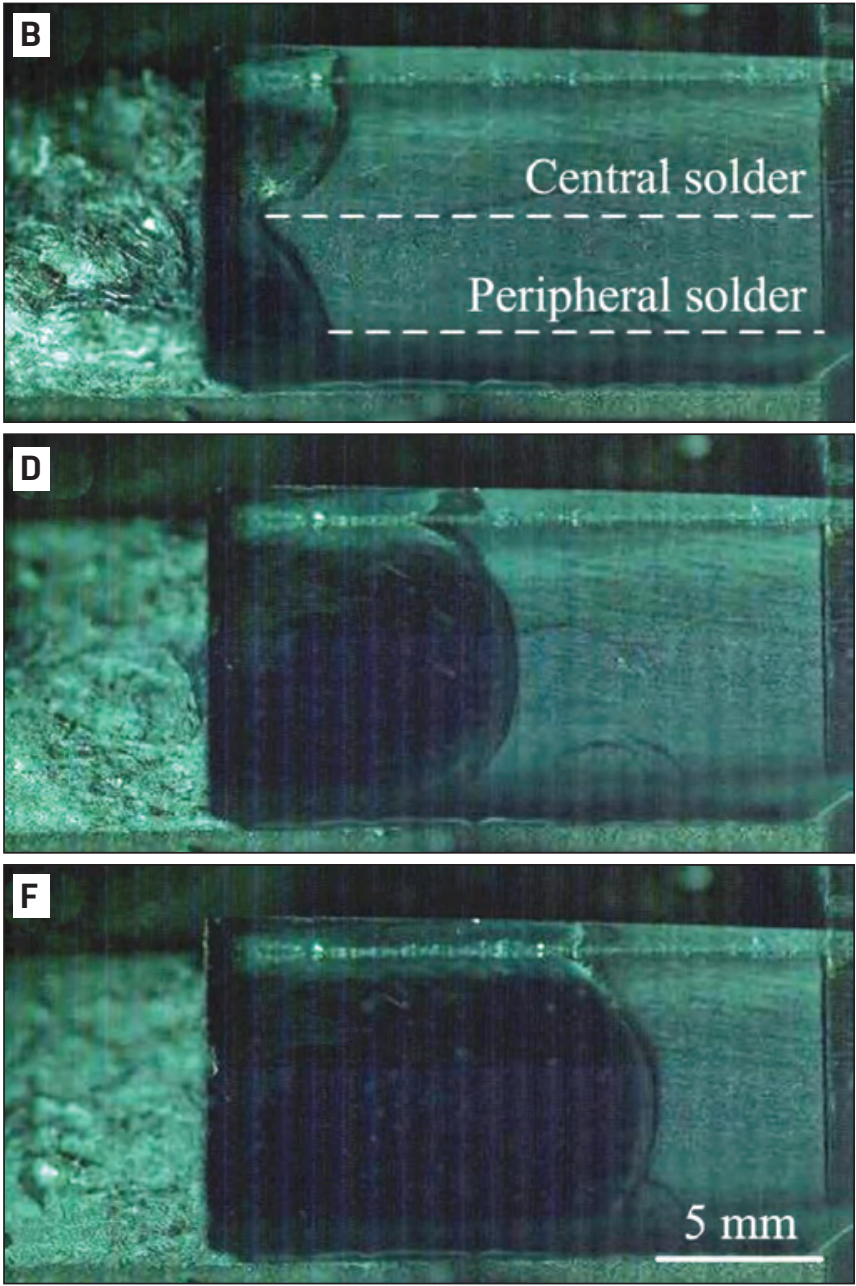

Fig. 2 - Filling of Sn-9Zn solder in 5056 Al capillary (Mode II, $500 \mu \mathrm{m}$ ): A - 0 s; B - 0.05 s; C - 0.1 s; D - 0.15 s; E - 0.2 s; F - 0.25 s.

\section{Ultrasonic Soldering Experiment}

The schematic of ultrasonic soldering is shown in Fig. 1. A transparent quartz glass was used as the top specimen, and metal materials were used as the bottom specimen. Solder filling could be observed through the top specimen. Ultrasonic waves were transmitted to the bottom specimen during soldering. Vibration status along the specimen would drastically affect solder filling. During the soldering experiment, the sonotrode was fixed against the bottom specimen with a pressure of $0.2 \mathrm{MPa}$ and operated at a frequency of 20 $\mathrm{kHz}$. The ultrasonic vibration system had a maximum rated power $(\mathrm{Pm})$ of $1000 \mathrm{~W}$. Three modes of power output were used: $1 / 3 \mathrm{Pm}$ (Mode I), $2 / 3 \mathrm{Pm}$ (Mode II), and Pm (Mode III). The clearance width between the glass and metal material was in the range of $200-700 \mu \mathrm{m}$.

In the ultrasonic soldering experiment, the solder material was placed on the bottom plate close to the clearance. Next, the solder was heated to the test temperature (approximately $30^{\circ} \mathrm{C}$ above the melting point of the solder) and then ultrasonic vibration was applied. A high-speed camera (Phantom V12.1) equipped with macro lens (Tokina $100 \mathrm{~mm}$ F2.8MACRO) was used to record the whole filling process. Images were acquired with the rate of 5000

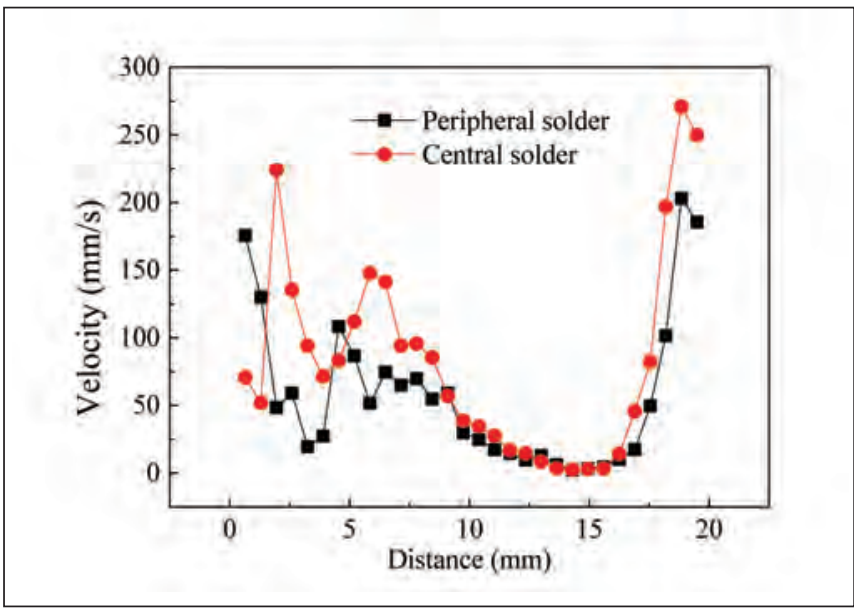

Fig. 3 - Variation in filling velocity with distance during filling (Sn-9Zn in 5056 Al capillary, Mode II, $500 \mu \mathrm{m}$ ).

frames/s and the resolution of $256 \times 256$ dots per inch. The filling velocity and process were analyzed by using the analytical software packaged with the high-speed camera. At least three samples were tested for each experimental condition. 


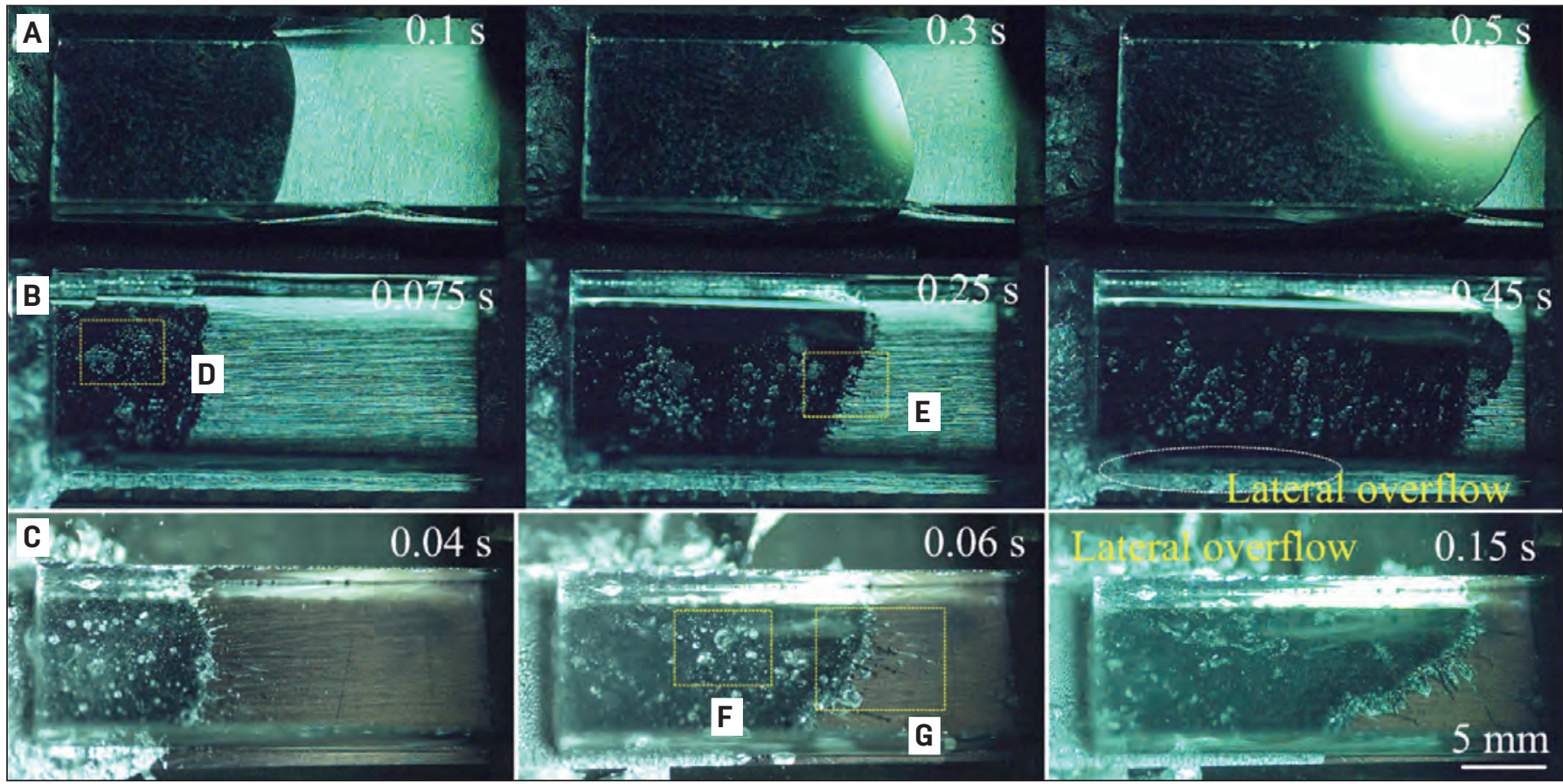

Fig. 4 - Filling progresses of (Sn-9Zn, Mode II, $200 \mu \mathrm{m})$ : A Pure Al; B - $5056 \mathrm{Al}$; and C - Fe36Ni; along with D- cavitation bubbles by using 5056 Al; E - sputtering by using 5056 Al; F - cavitation bubbles by using Fe36Ni; G - sputtering by using Fe36Ni.

\section{Results}

\section{Ultrasonic-Induced Filling}

Figure 2 shows the filling of the $5056 \mathrm{Al}$ clearance by the Sn-9Zn solder under different ultrasonic exposure durations, ultrasonic power mode of Mode II, clearance width of $500 \mu \mathrm{m}$, and heating temperature of $220^{\circ} \mathrm{C}$. Solder filling did not occur prior to the application of ultrasonic vibration but occurred immediately after ultrasonic application - Fig. 2A. During filling, peripheral solder advanced before the central solder - Fig. 2B. Subsequently, the movement of the central solder accelerated. As shown in Fig. 2C, the filler front appeared almost parallel after $0.15 \mathrm{~s}$ of ultrasonication. The velocity of the central solder was still greater than that of the peripheral solder, and the solder front became a convex interface at $0.2 \mathrm{~s}$, as shown in Fig. 2D. Then the entire interface moved forward as a stable convex front and decreased velocity - Fig. 2E. Filling observably accelerated at the final phase - Fig. 2F.

Figure 3 shows the changes in the velocity of the solder front at different positions during filling. The filling velocities reached high values at the initial stage of filling. Then, the filling velocities of the central and peripheral solders decreased, and the minimum filling velocities were obtained at the filling distance of $15 \mathrm{~mm}$. Subsequently, filling velocity drastically increased at the final stage. The central solder initially lagged behind the peripheral solder but then caught up quickly. In general, the filling velocities at different positions remained almost constant. As discussed in the follow-
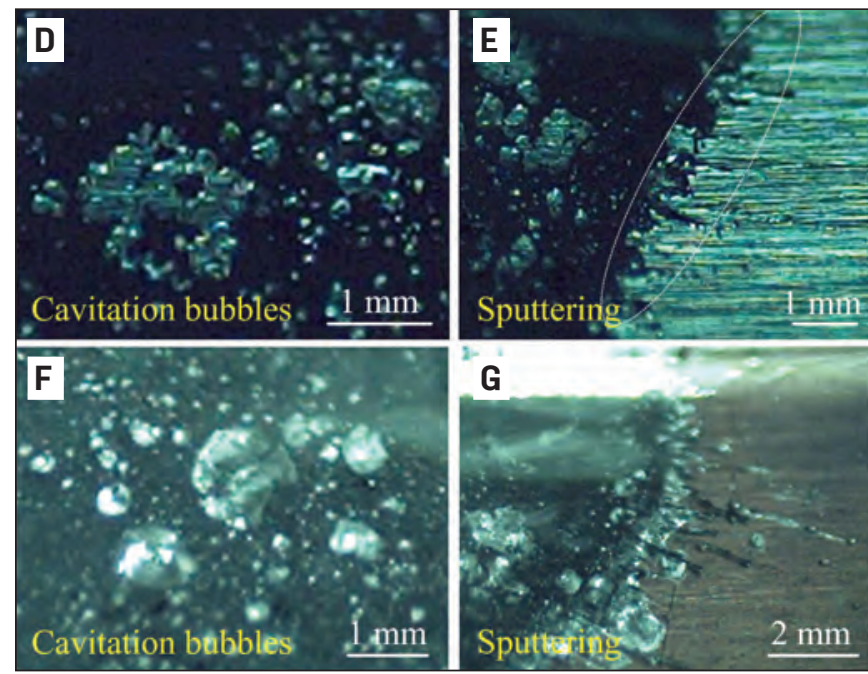

ing section, the filling velocity of the solder was closely related to the vibration conditions on the sheet surfaces.

\section{Factors Affecting Ultrasonic-Induced Filling}

This section presents an analysis of the influence of different factors, including filling velocity, cavitation, and sputtering phenomena, on filling.

\section{Influence of the Base Material}

Figure 4 shows the different filling progresses by using different base materials. The solder was Sn-9Zn. The clearance width was $200 \mu \mathrm{m}$, and the ultrasonic power mode was Mode II. When the base material was pure Al, filling was stable, and the solder proceeded as a mirror surface without observable sputtering at the solder front. At an ultrasonic time of $0.1 \mathrm{~s}$, the solder filled the half distance of the clearance - Fig. 4A. 


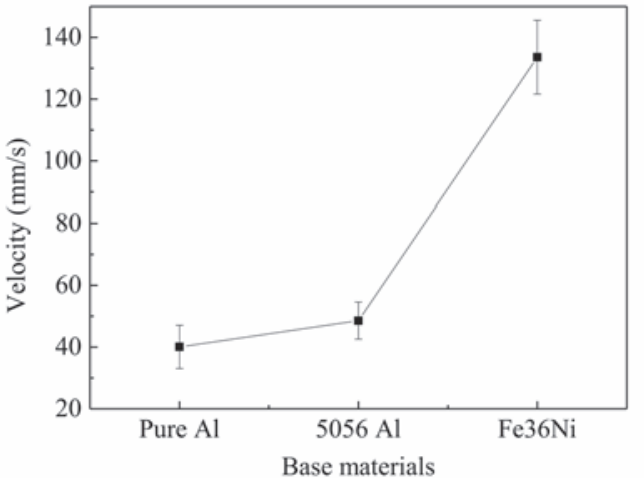

Fig. 5 - Filling velocities of different base materials (Sn-9Zn, $200 \mu \mathrm{m}$, Mode II).

The entire clearance was filled at the ultrasonic time of approximately $0.5 \mathrm{~s}$. Pronounced sputtering was observed at the solder front, and the sputtering droplets of Sn-9Zn were large by using $5056 \mathrm{Al}$ material - Fig. 4B. In addition to the sputtering phenomenon, numerous macroscopic cavitation bubbles were observed at the glass/solder interface - Fig. 4D and E. Meanwhile, continuous lateral overflow, namely, liquid solder flowing out of the lateral sides of the clearance, was observed during the filling progress. Filling with $\mathrm{Sn}-9 \mathrm{Zn}$ was faster than that on pure $\mathrm{Al}$ substrates, as presented in Fig. 4A. As shown in Fig. 4B, the entire clearance was filled at an ultrasonic time of approximately $0.45 \mathrm{~s}$.

Capillary filling with Fe36Ni was the most intense and exhibited the fastest rate (approximately $0.15 \mathrm{~s}$ as presented in Fig. 4C). It was also accompanied by severe sputtering (Fig. 4G) and lateral solder overflow and highly intense cavitation (Fig. 4F). The excessively intense ultrasonic strength even fractured the glass plate. Sputtering and subsequent overflow resulted in the serious depletion of solders and prevented the formation of a sound joint.

Figure 5 shows the average filling velocities of Sn-9Zn solder for different base materials. Filling velocity using pure $\mathrm{Al}$ was the slowest, followed by that for $5056 \mathrm{Al}$. The filling speed using Fe36Ni was the highest. However, fast filling velocity was associated with serious solder loss that resulted in the formation of pores and unfilled defects and prevented the formation of a sound solder joint.

\section{Influence of Ultrasonic Power}

Figure 6 shows the filling of Sn-9Zn solder in the pure $\mathrm{Al}$ capillary under different ultrasonic power modes. Filling was slow under Mode I - Fig. 6A. The solder failed to fill the entire capillary at the given time of $4 \mathrm{~s}$. As presented in Fig. 6A, the solder only filled one third of the capillary at the ultrasonication time of $1.6 \mathrm{~s}$. No macroscopic cavitation bubbles and sputtering were observed throughout the entirety of the filling processes. Filling velocity increased under high ultrasonic power - Fig. 6B and C. As illustrated in Fig. 6B, the solder filled half of the capillary at an ultrasonication time of $0.15 \mathrm{~s}$ under Mode II. Similar to that shown in Fig. 6A, macroscopic cavitation bubbles and sputtering were not observed during filling. Filling intensified under
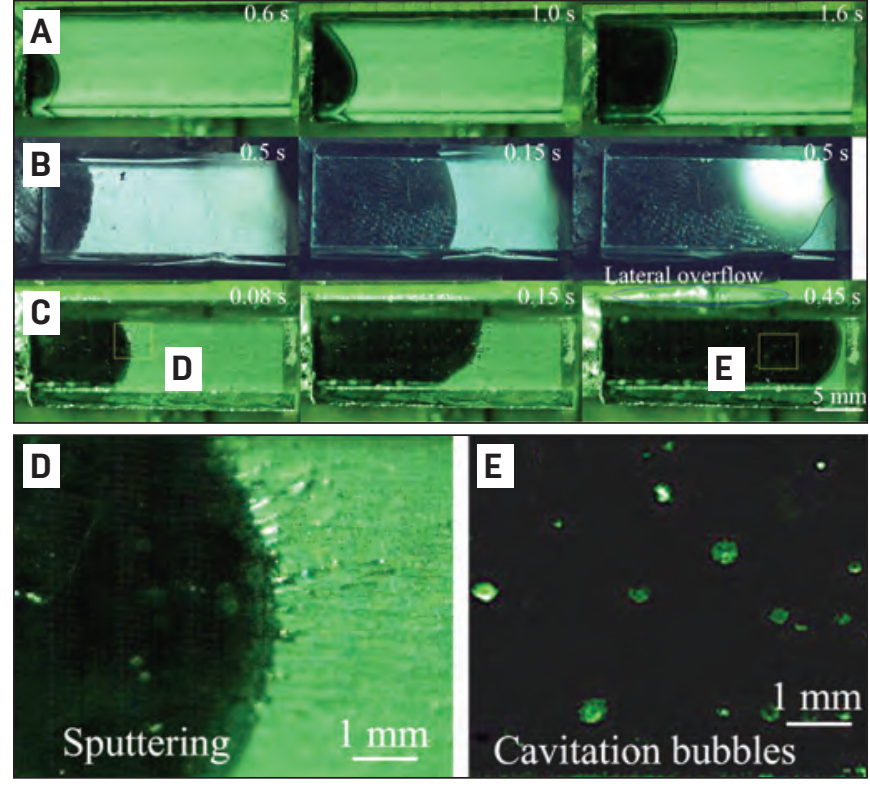

Fig. 6 - Filling of Sn-9Zn solder in pure $\mathrm{Al}(200 \mu \mathrm{m})$ under the following: A - Mode I; B - Mode II; C - Mode III; along with $D$ - sputtering; $E$ - cavitation bubbles.

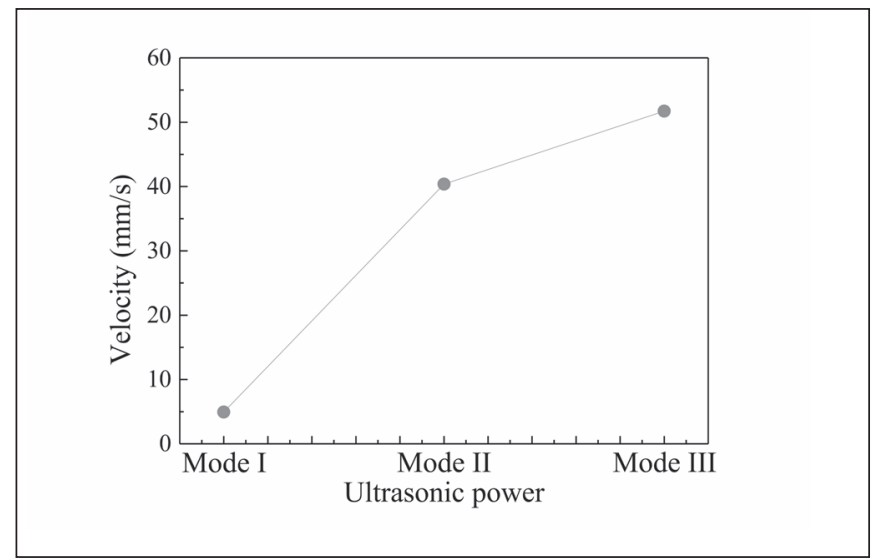

Fig. 7- Filling velocities of Sn-9Zn in pure Al clearance under different ultrasonic power modes $(200 \mu \mathrm{m})$.

Mode III. Sputtering (Fig. 6D) and some small cavitation bubbles (Fig. 6E) were observed at the solder front. The lateral overflow phenomenon also intensified - Fig. 6C.

The filling velocities of the $\mathrm{Sn}-9 \mathrm{Zn}$ solder in the pure $\mathrm{Al}$ clearance under different ultrasonic powers are provided in Fig. 7. Notably, the extremely low filling velocity of 4.9 $\mathrm{mm} / \mathrm{s}$ was observed under Mode I. Filling velocity drastically increased when the ultrasonic power increased to Mode II. Figure 7 shows that the filling velocity was $40.4 \mathrm{~mm} / \mathrm{s}$ under Mode II. Filling velocity slightly increased to $51.7 \mathrm{~mm} / \mathrm{s}$ under Mode III.

\section{Influence of Clearance Width}

Figure 8 presents the different stages of filling of Sn-9Zn on the base material $5056 \mathrm{Al}$ under different clearance sizes and Mode II. Filling was slow under these conditions. Filling under the channel width of $700 \mu \mathrm{m}$ is illustrated in Fig. 8A. 


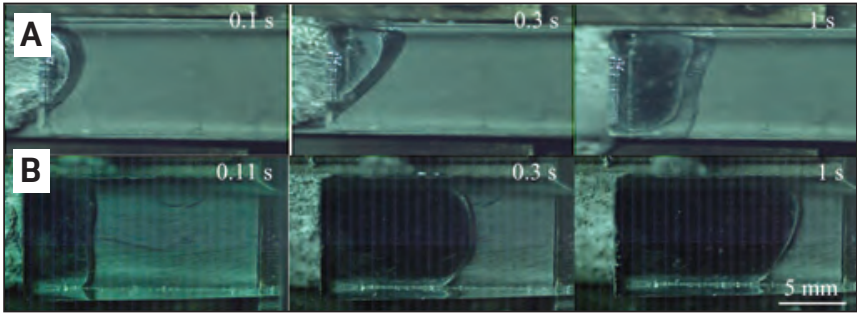

Fig. 8 - Filling under these different clearance widths (Mode II, Sn-9Zn): A - 700; B - 500 $\mu \mathrm{m}$.

Only one third of the clearance was filled at an ultrasonication time of $1 \mathrm{~s}$. As shown in Fig. 8B, filling velocity drastically increased as clearance width decreased. More than half of the clearance was filled at an ultrasonication time of $3 \mathrm{~s}-$ Fig. 8B. Filling considerably accelerated when the clearance width further decreased to $200 \mu \mathrm{m}$, as displayed in Fig. 4B.

Figure 9 shows the average filling velocities of the solder under different clearance widths. Notably, the filling speed exceeded $40 \mathrm{~mm} / \mathrm{s}$ under the channel width of $200 \mu \mathrm{m}$. Filling velocity considerably decreased as clearance width increased. The filling velocity was only $8.74 \mathrm{~mm} / \mathrm{s}$ under the channel width of $700 \mu \mathrm{m}$. The solder volume to be driven by ultrasonic power increased. Filling resistance accordingly increased when clearance width increased. In a large clearance, sound waves must propagate over a long distance from the lower to the upper base material. Acoustic attenuation intensified during sound wave propagation, and the sound field strength weakened. These two factors likely contributed to the reduction in filling rate.

\section{Influence of Solder Type}

$\mathrm{Sn}-4 \mathrm{Cu}$ and $\mathrm{Zn}-5 \mathrm{Al}$ solders were used in the experiment discussed in this section. The experiment was performed with $5056 \mathrm{Al}$ base material under Mode II. Figure 10 shows the filling processes of the different solders. The filling process of Sn$4 \mathrm{Cu}$ was considerably slower than that of $\mathrm{Sn}-9 \mathrm{Zn}$, as presented in Fig. 4B. Solder filling was hindered as viscosity increased. Numerous tiny cavitation bubbles were present in the clearance of the Sn-Cu solder. As illustrated in Fig. 10A, the filling front was irregular, and the inconsistent forward movement of the solder front may surround some gas to form large "trapped bubbles." The inconsistency of the solder front also resulted in the introduction of air in the solder joint, which generated additional stable air bubbles that could not be discharged and were likely to form porosity. The filling process of $\mathrm{Zn}-5 \mathrm{Al}$ is given in Fig. 10B. The filling process of $\mathrm{Zn}-\mathrm{Al}$ was considerably slower than that of $\mathrm{Sn}-9 \mathrm{Zn}$ and $\mathrm{Sn}-4 \mathrm{Cu}$. The $\mathrm{Zn}-5 \mathrm{Al}$ solder cannot fill the entire clearance at the ultrasonication time of 4 s. Minuscule cavitation bubbles, but not air bubbles, were observed in the clearance.

The viscosities and average filling velocities of the solders are presented in Fig. 11. The viscosities of the solders were obtained from references (Refs. 40-42). Solder filling velocities were inversely proportional to solder viscosities. To illustrate, the Sn-9Zn solder had the lowest viscosity and the highest filling velocity. By contrast, the $\mathrm{Zn}-5 \mathrm{Al}$ solder had the highest viscosity but the lowest filling velocity. Therefore, filling clearances with highly viscous solders will be difficult.

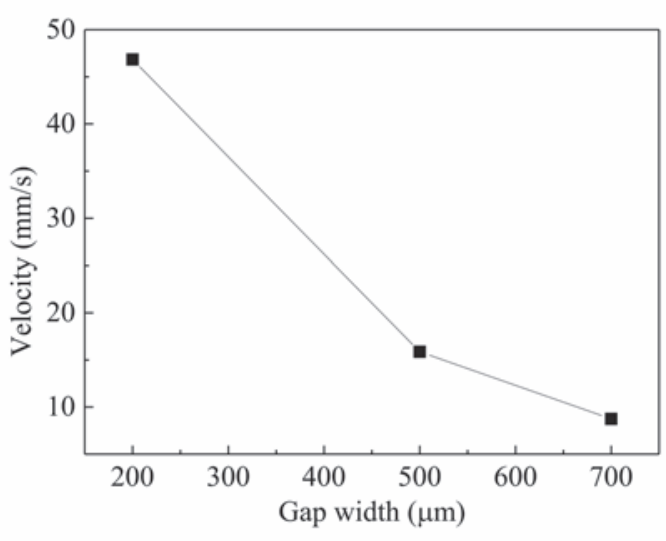

Fig. 9 - Variation in filling velocity with clearance width (Mode II, Sn-9Zn).

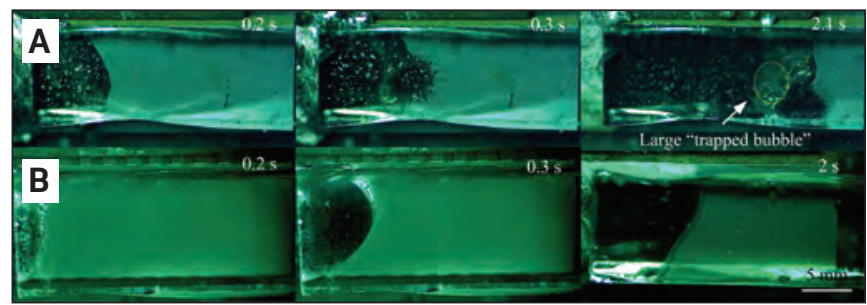

Fig. 10 - Filling processes (Mode II, $200 \mu \mathrm{m}$ ) of the following: A - Sn-4Cu; B - Zn-5Al.

The surface vibration of the base material, which has its own specific characteristics, has a crucial effect on the dynamics of liquid solders in capillaries when ultrasonic energy is input from a solid substrate. The surface vibration strength of the base material must be sufficiently high to drive the liquid solder to penetrate the capillary. However, excessively high ultrasonic strength might cause serious lateral overflow and solder sputtering during capillary filling and prevent the production of sound joints by inducing heavy solder loss. In accordance with acoustic law, different base materials have different acoustic propagation characteristics. Base data on the acoustic distribution of the substrate surface must be acquired to guide the production of sound joints through soldering. For a given base material, the input ultrasonic strength, the joint clearance, and other factors that affect the sound strength in the solder must be well coordinated to ensure full capillary filling and adequate cavitation strength for the removal of surface oxide films.

\section{Discussion}

\section{Surface Vibration of the Base Material and Its Influence on Solder Filling}

In our previous work (Ref. 43), we found that solder spreading/wetting on base material largely depended on the vibration intensity of the base material surface. Large spreading area and complete oxide removal were observed at regions of high vibration intensity. Therefore, the vibration 


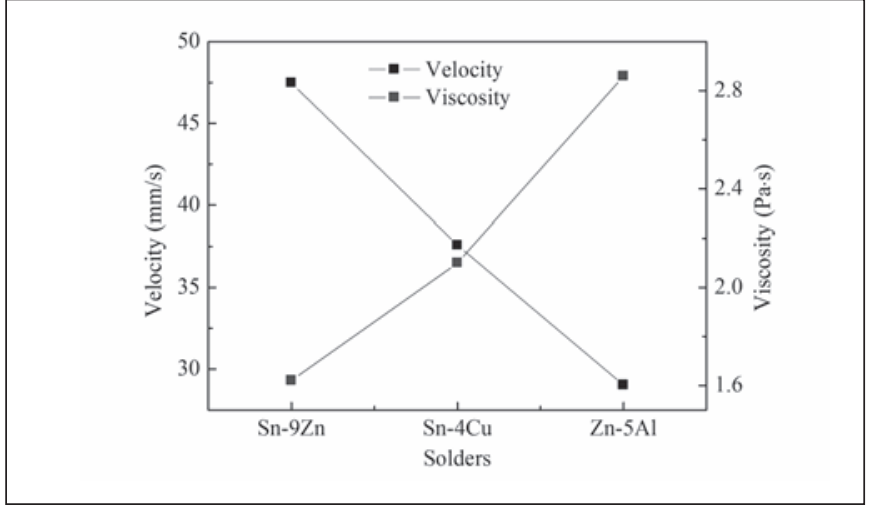

Fig. $11-$ Solder viscosities and average filling velocities of different solder materials (Mode II, $200 \mu \mathrm{m}$ ).

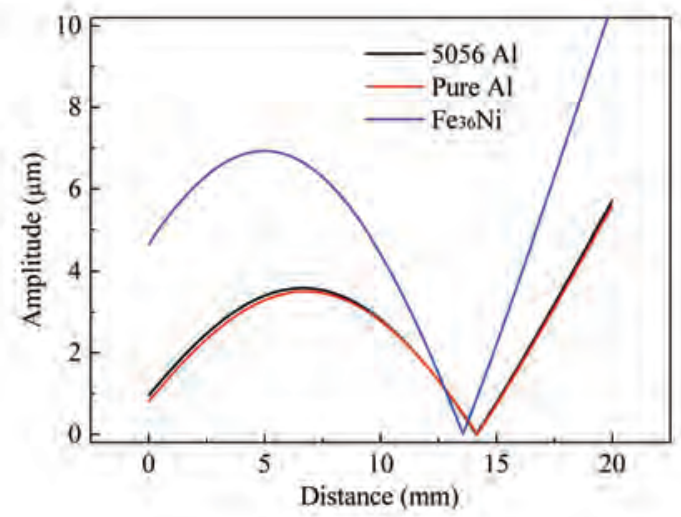

Fig. 13 - Surface amplitude curves of the filling area along the $x$-axis for different base metals.

intensity of the base material has a definitive effect on solder filling velocity.

Sound intensity is used to characterize ultrasound propagation in solids. When sound wave frequency and excitation amplitude are constant, sound intensity in different solids is proportional to the characteristic impedance of the solid materials, as shown in Equation 1.

$$
I=\frac{1}{2} z_{0} A^{2} \omega^{2}
$$

where $I$ is sound intensity, $z_{0}$ is the characteristic impedance of the solid material, $A$ is excitation amplitude, and $\omega$ is acoustic angular frequency.

The characteristic impedance of the material is mainly dependent on the physical properties of the material itself, as shown in Equation 2.

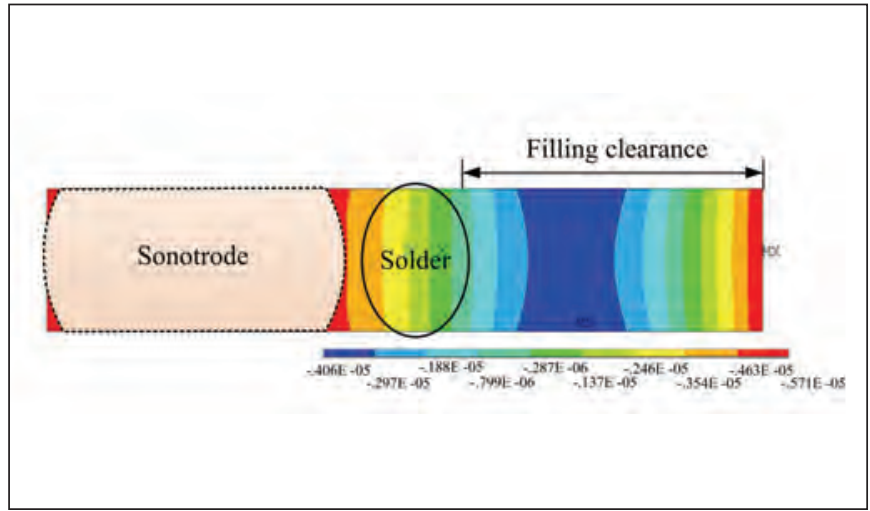

Fig. 12 - Vibration calculation results for the 5056 Al alloy surface.

$$
z_{0}=\rho_{0} c_{0}=\rho_{0} \sqrt{\frac{E}{\rho_{0}}}=\sqrt{\rho_{0} E}
$$

where $\rho_{0}$ is material density, $c_{0}$ is the propagation velocity of sound waves in the material, and $E$ is the elastic modulus of the material. Therefore, acoustic transmission intensity will differ among different materials. The characteristic impedances of different materials were calculated with Equation 2 and are given in Table 2.

Figure 12 shows the vibration on the $5056 \mathrm{Al}$ surface under Mode II at $220^{\circ} \mathrm{C}$. Ultrasonic vibration was applied to the left side of the specimen (dotted area in Fig. 12). The length of the filling area in the filling experiment was approximately $20 \mathrm{~mm}$. As illustrated in Fig. 12, the vibration nephogram was symmetrical along the $\mathrm{x}$-axis and was divided into several regions with different colors, which represent different amplitudes. The maximum amplitude was observed at the red zone at the ending of the filling area, and the minimum amplitude was observed at the green area. The solder was placed near the blue area near the filling area. The amplitude of this area gradually increased along the positive $\mathrm{x}$-axis axis direction. Therefore, the filling velocity was relatively fast at the initial filling stage (Fig. 3). In the filling area, the vibration amplitude first decreased and then increased along the positive $\mathrm{x}$-axis direction. The law governing the variation of the amplitude inside the filling area corresponded with the filling velocity illustrated in Fig. 3. Merging Figs. 2, 3, and 12 revealed that the filling velocity along the axial direction corresponded to the change in vibration distribution on the plate surface. That is, the liquid solder advanced fast where the surface vibration was strong and moved slowly where the surface vibration was weak. Also, it could be deduced that the presence of liquid solder in the clearance did not alter the vibration pattern of the base material. The liquid solder in the clearance might slightly depress the surface vibration of the base material.

Table 2 - Characteristic Impedance of the Base Materials

\begin{tabular}{cccc} 
Material & Pure Al & $5056 \mathrm{Al}$ & Fe36Ni \\
\hline $\begin{array}{c}\text { Characteristic } \\
\text { Impedance }\end{array}$ & $13.64 \times 10^{3}$ & $13.76 \times 10^{3}$ & $34.15 \times 10^{3}$ \\
\hline
\end{tabular}


However, the effect could be neglected because the solder film was only hundreds of micrometers in thickness.

As illustrated in Fig. 2B, the peripheral solder had higher filling velocity than the central solder at the ultrasonication time of $0.05 \mathrm{~s}$ because vibration intensity at the base material periphery was stronger than that at the base material center. As previously discussed, strong vibration increased filling velocity. Thus, the filling process of the peripheral solder accelerated. As filling continued, the filling velocity of the central solder increased and gradually exceeded that of the peripheral solder - Fig. 3 . The solder front became convex at an ultrasonication time of $0.2 \mathrm{~s}$ (Fig. 2D) because sound pressure inside the side solder decreased. Sound pressure drastically decreased because the peripheral solder was in direct contact with air. Therefore, the filling velocity of the side solder decreased. Meanwhile, sound pressure inside the central solder remained at a high level because it did not come in contact with air. Thus, the velocity of the central solder gradually became higher than that of the side solder.

Given this theory, the solder front should remain convex during the whole filling process. However, Fig. 4 shows that the solder filling front did not follow a strict convex morphology throughout the entire filling process. This was because the sustained strong ultrasonic vibration might cause unparalleling of the two substrate plates, resulting in the unevenness of the clearance width. Thus, the solder filling velocity was influenced locally, and the convex morphology of the filling front was spoiled.

Figure 13 shows the variation curves of the amplitude along the $\mathrm{x}$-axis of the filling areas of the different base materials. In general, amplitudes on the base materials first increased, then decreased, and finally increased. The vibration intensity of the pure $\mathrm{Al}$ base material was the lowest, followed by that of the $5056 \mathrm{Al}$ substrate. Fe36Ni exhibited the strongest vibration intensity. The vibration intensity on the substrate was mainly determined by the characteristic impedance of the substrates. Pure $\mathrm{Al}$ had the lowest characteristic impedance (Table 2). Thus, the amplitudes on the pure $\mathrm{Al}$ surface were the weakest. By contrast, the characteristic impedance of Fe36Ni was the highest and therefore resulted in the strongest surface vibration intensity. Merging Figs. 4 and 5 with Fig. 13 revealed that the filling velocities obtained by different base materials corresponded well to the vibration intensity on substrate surfaces. Strong vibration intensity indicates fast filling. Additionally, it's more obvious that the filling velocity along the clearance corresponded well to the vibration distribution on the base material surface by combining Figs. 3 and 13 .

\section{Influence of Ultrasonic Power}

Vibration intensity on the base material surface was not only determined by impedance but also by the input ultrasonic power. We previously found that strong vibration can be obtained under high ultrasonic power, regardless of the fact the vibration pattern (as Figs. 12 and 13 depict) would not be altered by the input power level (Refs. 43, 44). Therefore, the vibration intensity on pure $\mathrm{Al}$ was the weakest under Mode I and the strongest under Mode III. Strong vibration accelerated solder filling, as shown in Figs. 6 and 7.
In addition, as presented in Fig. 6, no cavitation bubbles and sputtering occurred during filling under Modes I and II. Nevertheless, cavitation bubbles and sputtering were observed under Mode III. The presence of cavitation bubbles and sputtering could be attributed to the sound pressures induced inside the solders under different ultrasonic powers. The sound pressure inside the solders did not reach the cavitation threshold under Modes I and II but reached the cavitation threshold at some regions under Mode III. Ultrasonic power was transmitted from the sonotrode to the solder. We assumed that solder volume was the same at different powers because the clearance width was unchanged. Therefore, the ultrasonic vibration intensity inside the solder under Mode III was thrice that under Mode I. High ultrasonic intensity inside the solder resulted in cavitation and sputtering at the solder front and increased the fillingdriving force.

\section{Influence of Clearance Width}

As shown in Figs. 8 and 9, the clearance width between base materials had a drastic influence on filling velocity. Small clearance width resulted in faster filling velocity. This phenomenon can be attributed to the generation of different sound pressures inside clearances with different widths. Ultrasound first propagated along the lower sheet, then transmitted into the solder, and finally reached the upper sheet. During propagation, ultrasound can fluctuate when passing through different media and is reflected after reaching the medium boundaries. Ultrasound exhibited fluctuations and different reflection times inside clearances with small widths. These phenomena increased sound pressure inside the solder. High sound pressure promoted cavitation. Thus, numerous cavitation bubbles were observed at the sol$\mathrm{der} /$ base material surface under the channel width of 200 $\mu \mathrm{m}$ but not under the channel widths of 500 and $700 \mu \mathrm{m}$ because of reductions in sound pressure. Cavitation caused by high sound pressure promoted capillary filling. Therefore, fast filling was obtained under the channel width of $200 \mu \mathrm{m}$. Although no cavitation was observed under the clearance width of $500 \mu \mathrm{m}$, the sound pressure inside the clearance was still considerably larger than that at $700 \mu \mathrm{m}$. Thus, fast filling speed was observed.

\section{Determination of the Necessity of Cavitation for Ultrasonic Capillary}

In this work, when using $5056 \mathrm{Al}$ as the base material, cavitation bubbles were observed during filling under a channel width of $200 \mu \mathrm{m}$. However, cavitation bubbles were absent and slow filling was observed under channel widths of 500 and $700 \mu \mathrm{m}$. Similarly, for the filling process in pure $\mathrm{Al}$ clearances, as shown in Fig. 6A and B, the liquid solder rapidly advanced in the absence of cavitation. Therefore, we concluded that cavitation is not an essential condition for horizontal capillary movement. This finding is quite different from that found in Ref. 37, which claimed that the collapse of cavitation bubbles in the vicinity of the inlet microcapillary inlet was responsible for the ultrasonic capillary effect.

In our previous work (Ref. 45), we observed the ultra- 
sonic-induced ascent of the $\mathrm{Sn}-9 \mathrm{Zn}$ solder in a vertical Al alloy capillary above the normal solder level. As the solder rise in the capillary was nearly independent of its wettability to the aluminum substrate, its driving force was speculated to be a pressure deviation between the solder bath and the solder in the clearance. This was examined by using a water/glass sonocapillary system, in which the acoustic pressure outside and inside the capillary was measured by using an acoustic pressure meter. The test results showed that a considerable decline of acoustic pressure did exist from the outside to the inside of the capillary. A model for the propagation of ultrasonic waves in the capillary was proposed and the acoustic pressure drop in the capillary was attributed to the fast attenuation of ultrasonic energy when ultrasonic waves transmitted from the solder bath into the capillary. Similarly, the horizontal ultrasonic capillary observed in the present work should follow the same mechanism, although the gravity played a different role on the solder filling. Under ultrasonication, ultrasonic waves transmitted into the solder droplet located at the entrance of the joint clearance. The solder droplet subjected to ultrasonic vibration deformed and spread on the substrate, and some of the liquid solder penetrated into the clearance. Once there existed liquid solder (even a small volume) in the clearance, acoustic pressure differential came into being between the outside and inside of the clearance, and the liquid solder outside the capillary would be driven to continuously fill into the joint clearance. It could be seen from the results shown before (Figs. 4-7, 12, 13) that faster solder filling was obtained under stronger surface vibration of base materials. That means the acoustic pressure differential became larger when the liquid solder was agitated more intensely by ultrasonic. When the agitation was intense enough, cavitation took place in the liquid solder. Therefore, cavitation was an accompanying phenomenon of solder filling, other than the cause of solder filling.

\section{Conclusions}

1. Solder filling velocity was closely related to the vibration intensity of the base materials. Solder filling velocity first decreased and then increased. Fe36Ni had the strongest vibration intensity on its surface and therefore exhibited the fastest filling process, which was accompanied by severe sputtering and cavitation.

2. High power accelerated filling by increasing vibration intensity on the base material surfaces. Narrow clearance width accelerated the filling process by increasing ultrasonic power inside the solder. Highly viscous solders had low filling velocities.

3. Cavitation is not an essential condition for horizontal capillary. Similar to vertical capillary, solder filling is driven by the acoustic pressure differential between the outside and inside of the capillary.

\section{Acknowledgments}

This project was supported by the National Natural Science Foundation of China (No. 51574099, 51435004).

\section{References}

1. Graff, K. 1977. Marcosonics in industry: Ultrasonic soldering. Ultrasonics 15(2): 75-81.

2. Saxty, P. 1999. Ultrasonic soldering - A farewell to flux. Welding and Metal Fabrication 67(3): 15-17.

3. Antonevich, J. N. 1976. Fundamentals of ultrasonic soldering. Welding Journal 55(7): 200-s to 207-s.

4. Li, Y., Zhao, W., Leng, X., Fu, Q., Wang, L., and Yan, J. 2011. Microstructure evolution and mechanical properties of ultrasonicassisted soldering joints of 2024 aluminum alloys. Transactions of Nonferrous Metals Society of China 21: 1937-1943.

5. Chen, X., Yan, J., Ren, S., Wei, J., and Wang, Q. 2013. Microstructure and mechanical properties of Ti-6Al-4V/Al1060 joints by ultrasonic-assisted brazing in air. Materials Letters 95: 197-200.

6. Kim, J. H., Lee, J., and Yoo, C. D. 2005. Soldering method using longitudinal ultrasonic. IEEE Transactions on Components and Packaging Technologies 28(3): 493-498.

7. Fuchs, F. J. 1979. Ultrasonics in electronic soldering applications. Electronic Packaging and Production 11: 124-132.

8. Vianco, P. T., Hosking, F. M., and Rejent, J. A. 1996. Ultrasonic soldering for structural and electronic applications. Welding Journal 75(11): 343-s to 355-s.

9. Gunkel, R. W. 1979. Solder aluminum joints ultrasonically. Welding Design \& Fabrication 58(9): 90-92.

10. Graff, K. 2007. Ultrasonic soldering and brazing. EWI Insights, Columbus, Ohio.

11. Jenkins, W. B. 1976. Fluxless soldering of aluminum heat exchangers. Welding Journal 55(1): 28-s to 35-s.

12. Lanin, V. L. 2001. Ultrasonic soldering in electronics. Ultrasonics Sonochemistry 8: 379-385.

13. Yan, J., Zhao, W., Xu, H., Li, D., Xu, Z., Yang, S., and Ma, Z. 2009. Ultrasonic brazing of aluminum alloy and aluminum matrix composite. Patent No.: US 7, 624, 906 B2.

14. Faridi, H. R., Devletian, J. H., and Le, H. P. 2000. A new look at flux-free ultrasonic soldering. Welding Journal 79(9): 41-s to 45-s.

15. Weis, S., Hoyer, I., and Wielage. B. 2008. Joining of highstrength aluminum-based materials with tin-based solders. Welding Journal 87(3): 35-s to 37-s.

16. Nagaoka, T., Morisada, Y., Fukusumi, M., and Takemoto, T. 2011. Selection of soldering temperature for ultrasonic-assisted soldering of 5056 aluminum alloy using $\mathrm{Zn}$-Al system solders. Journal of Materials Processing Technology 211: 1534-1539.

17. Nagaoka, T., Morisada, Y., Fukusumi, M., and Takemoto, T. 2009. Strength and corrosion resistance of a solder joint in ultrasonic soldering of aluminum using quasi-melting solder. Welding International 23(12): 879-885.

18. Tillmann, W., Zimpel, M., Dias, N. F. L., Pfeiffer, J., Wojarski, L., and Xu, Z. 2015. Mechanical and microstructural analysis of ultrasonically assisted induction-brazed TiAl6V4 joints. Weld World 59: 901-909.

19. Elrefaey, A., Wojarski, L., Pfeiffer, J., and Tillmann, W. 2013. Preliminary investigation on ultrasonic assisted brazing of titanium and titanium/stainless steel joints. Welding Journal 92(5): 148$s$ to $153-s$.

20. Xu, Z., Ma, L., Yan, J., Yang, S., and Du, S. 2012. Wetting and oxidation during ultrasonic soldering of an alumina reinforced aluminum-copper-magnesium (2024 Al) matrix composite. Composites: Part A 43: 407-414.

21. Zhao, W., Yan, J., Yang W., and Yang, S. Capillary filling process during ultrasonically brazing of aluminum matrix composites. Science and Technology of Welding and Joining 13(1): 66-69.

22. Rozina, E. Yu. 2002. Effect of pulsed ultrasonic field on the filling of a capillary with a liquid. Colloid Journal 64(3): 359-363.

23. Matsunaga, T., Ogata, K., Hatayama, T., Shinozaki, K., and 
Yoshida, M. 2007. Effect of acoustic cavitation on ease of infiltration of molten aluminum alloys into carbon fiber bundles using ultrasonic infiltration method. Composites: Part A 38: 771-778.

24. Yin, X., Han, P., Lu, X., and Wang, Y. A review on the dewaterability of bio-sludge and ultrasound pretreatment. Ultrasonics Sonochemistry 11: 337-348.

25. Kyllonen, H. M., Pirkonen, P., and Nystrom, M. 2005. Membrane filtration enhanced by ultrasound: A review. Desalination 181: 319-335.

26. Pirkonen, P., Grönroos, A., Heikkinen, J., and Ekberg, B. 2010. Ultrasound assisted cleaning of ceramic capillary filter. Ultrasonics Sonochemistry 17: 1060-1065.

27. Hawkes, J. J., Limaye, M. S., and Coakley, W. T. 1997. Filtration of bacteria and yeast by ultrasound-enhanced sedimentation. Journal of Applied Microbiology 82: 39-47.

28. Lee, P. D., and Sridhar, S. 2000. Direct observation of the effect of strontium on porosity formation during the solidification of aluminium-silicon alloys. International Journal of Cast Metals Research 13(4): 185-198.

29. Tzanakis, I., Xu, W. W., Lebon, G. S. B., Eskin, D. G., Pericleous, K., and Lee, P. D. 2015. In situ synchrotron radiography and spectrum analysis of transient cavitation bubbles in molten aluminium alloy. Physics Procedia 70: 841-845.

30. Dezhkunov, N. V., and Leighton, T. G. 2004. Study into correlation between the ultrasonic capillary effect and sonoluminescence. Journal of Engineering Physics and Thermophysics 77(1): 53-61.

31. Huang, Y., Shah, A., Mayer, M., Zhou, N., and Persic, J. 2010. Effect of ultrasonic capillary dynamics on the mechanics of thermosonic ball bonding. IEEE Transactions on Ultrasonics, Ferroelectrics, and Frequency Control 57(1): 241-252.

32. Malykh, N., Petrov, V., and Sankin, G. 2003. On sonocapillary effect. WCU 2003, Paris, September 7-10.

33. Sankin, G. N., and Malykh, N. V. 2005. Force acting on a cylinder under ultrasonically induced cavitation. Technical Physics 50(7): 918-923.

34. Tamura, S., and Hatakeyama, M. 2013. The role of acoustic cavitation in liquid pressurization in narrow tubes. Journal of Applied Physics 113: 144905. DOI: 10.1063/1.4801422

35. Konovalov, E. G., and Germanovich, I. K. 1962. The ultrasonic capillary effect. Dokl. Akad. Nauk Belorus. SSR 6(8): 492, 493.

36. Rozin, Yu. P., Tikhonova, V. S., and Kostucheck, M. N. 1975.
About extremely high constant pressures in the capillary placed close to ultrasonic emitter. Ukr. J. Phys. 20: 214-220.

37. Tzanakis, I., Xu, W. W., Eskin, D. G., Lee, P. D., and Kotsovinos, N. 2015. In situ observation and analysis of ultrasonic capillary effect in molten aluminium. Ultrasonics Sonochemistry 27: 72 80.

38. Hu, J., Tan, C., and Hu, W. 2007. Ultrasonic microfluidic transportation based on a twisted bundle of thin metal wires. Sensors and Actuators A 135: 811-817.

39. Cecchini, M., Girardo, S., Pisignano, D., Cingolani, R., and Beltram, F. 2008. Acoustic-counterflow microfluidics by surface acoustic waves. Applied Physics Letters 92: 104103.

40. Tomasz, G., and Janusz, P. 2013. Phsicochemical properties of Sn-Zn and SCA + Bi alloys. Journal of Electronic Materials 42(2): 288-293.

41. Nunes, V. M. B., and Lourenco, M. J. V. 2010. Viscosity of industrially important Al-Zn alloy. International Journal of Themophysics 31: 2348-2360.

42. Zhao, N., Huang, M. L., Ma, H.,T., Pan, X. M. and Liu, X.Y. 2013. Viscosities and wetting behaviors of $\mathrm{Sn}-\mathrm{Cu}$ solders. Acta Physica Sinica 62(8): 086601.

43. Ma, L., Xu, Z., Zheng, K., Yan, J., and Yang, S. 2014. Vibration characteristics of aluminum surface subjected to ultrasonic waves and their effect on wetting behavior of solder droplets. Ultrasonics 54: 929-937.

44. Li, Z., Xu, Z., Ma, L., Wang, S., Liu, X., and Yan, J. 2018. Cavitation at filler metal/substrate interface during ultrasonicassisted soldering. Part I: Cavitation characteristics. Ultrasonics Sonochemistry 49: 249-259.

45. Xu, Z., Ma, L., Yang, J., Zhang, J., and Yan, J. 2016. Ultrasonic induced rising and wetting of a Sn-Zn filler in an aluminum joint. Welding Journal 95(7): 264-s to 272-s.
ZHIWU XU (xuzw@hit.edu.cn), ZHENGWEI LI (qingdaolzw- @163.com), LIN MA, ZIWEI CAO, and JUCHUN YAN are with the State Key Laboratory of Advanced Welding and Joining, Harbin Institute of Technology, Harbin, China. JIANGUO YANG is with the Institute of Process Equipment and Control Engineering, Zhe- jiang University of Technology, Hangzhou, China.

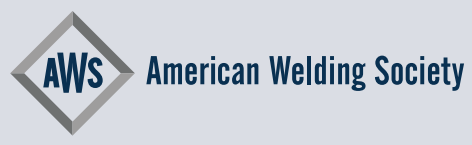

\section{Authors: Submit Research Papers Online}

Peer review of research papers is now managed through an online sytem using Editorial Manager software. Papers can be submitted into the system directly from the Welding Journal page on the AWS website (aws.org) by clicking on "submit papers." You can also access the new site direclty at editorialmanager.com/wj/. Follow the instructions to register or log in. This online system streamlines the review process, and makes it easier to submit papers and track their progress. By publishing in the Welding Journal, more than 70,000 members will receive the results of your research.

Additionally, your full paper is posted on the American Welding Society website for FREE access around the globe. There are no page charges, and articles are published in full color. By far, the most people, at the least cost, will recognize your research when you publish in the world-respected Welding Journal. 